\section{RHABDOMYOSARCOMA OF THE CERVIX IN TEENAGERS - IS FERTILITY PRESERVATION A FEASIBLE OPTION?}

${ }^{1}$ Felicia Elena Buruiana, ${ }^{2}$ Bindiya Gupta, 'Kavita Singh. ${ }^{1}$ PanBirmingham Gynaecological Cancer Centre, Birmingham City Hospital; Gynaecological Oncology, Birmingham, UK; ${ }^{2} T$ he Pan-Birmingham Gynaecological Oncology Centre, City Hospital; PanBirmingham Gynaecological Cancer Centre, Birmingham City Hospital; Gynaecological Oncology, Birmingham, UK

\subsection{6/ijgc-2020-ESG0.25}

Introduction/Background Embryonal rhabdomyosarcoma (RMS) of the cervix is a rare entity, encountered mainly in the first two decades of life. The literature consists mainly of case reports and few small case series, and no standard treatment guidelines are available. As this is a disease of adolescence, fertility preservation in well selected cases is of paramount importance.

Methodology We report 3 cases of embryonal RMS of the cervix in adolescents, along with their clinical presentation, histopathological features, diagnosis, management tailored to individual cases.

Results To date, two of the patients have been followed for 5 years and the remaining 1 for 2 years.

They all remained asymptomatic, with no evidence of recurrent disease on clinical examination and MRI.

Conclusion The embryonal type of cervical RMS is the most frequent type in this age group. Cervical RMS have good prognosis as usually they present early due to clinical features of bleeding or a mass protruding through the vagina. It should be considered as differential diagnosis for continuous vaginal bleeding in a teenager and should be investigated appropriately. The patients diagnosed with RMS should be managed by multidisciplinary team at cancer centre for best outcomes. Given the young age at diagnosis, fertility sparing treatment maintaining the oncological safety is of paramount importance and is associated with long term survival.

Disclosures Nil to disclose.

\section{RISK FACTORS FOR MARGIN POSITIVITY IN LEEP}

${ }^{1}$ Ozlem Celik, ${ }^{1}$ Halise Meltem Batur, ${ }^{1}$ Anıl Can Yalçn, ${ }^{1}$ Nazlı Can Yalçn, ${ }^{2}$ Utku Akgör, ${ }^{2}$ Nejat Ozgul, ${ }^{2} \mathrm{M}$ Coskun Salman, ${ }^{2}$ Murat Gultekin. ${ }^{1}$ Hacettepe University Faculty of Medicine; Department of Obstetrics and Gynecology; ${ }^{2}$ Hacettepe University Faculty of Medicine; Department of Gynecological Oncology

\subsection{6/ijgc-2020-ESGO.26}

Introduction/Background Loop electrosurgical excision procedure (LEEP) is the most frequently used therapeutic approach in pre-invasive cervical diseases. Surgical margin positivity is a big debate among gynecologists and there are several reports showing the importance of HPV 16-18, pap-smear results, age of the patient, or size of the lesion. This study evaluates the risk factors for surgical margin positivity among patients who were subjected to LEEP for pre-invasive cervical lesions in a tertiary colposcopy center.

Methodology Patients with pre-invasive cervical lesions who underwent LEEP were retrospectively evaluated. Patients who were not tested for high-risk HPV were excluded. Patients were evaluated for margin positivity with respect to pap-smear result (normal vs. $\geq$ ASC-US), age ( $\leq 40$ vs. $>40$ years), lesion size $(\leq 2$ $\mathrm{cm}$ vs. $>2 \mathrm{~cm})$ and HPV type (16-18 vs. other high-risk HPV). Student-t test and chi-square test were used for comparison.
Abstract 346 Table 1 Comparison of LEEP margine positive vs. negative cases

\begin{tabular}{|l|c|c|c}
\hline & $\begin{array}{c}\text { Margine positive (+) } \\
\mathrm{n}(\%)\end{array}$ & $\begin{array}{c}\text { Margine negative }(-) \\
\mathrm{n}(\%)\end{array}$ & $\mathrm{p}$ \\
\hline Age (mean) & 41,4 & 40,5 & 0,4 \\
\hline Age & & & 0,5 \\
\hline$\leq 40$ & $39(49,4)$ & $130(53,7)$ & 0,5 \\
\hline$>40$ & $40(50,6)$ & $112(46,3)$ & $<0,001$ \\
\hline Pap-smear & & & $<0,001$ \\
\hline Normal & $21(26,6)$ & $123(51,0)$ & $<0,001$ \\
\hline$\geq$ ASC-US & $58(73,4)$ & $118(49,0)$ & $<0,001$ \\
\hline HPV & & & 0,8 \\
\hline $16+/$-18 & $60(75,9)$ & $105(43,4)$ & 0,8 \\
\hline Others & $19(24,1)$ & $137(56,6)$ & 0,06 \\
\hline Lesion size & & & $180(74,4)$ \\
\hline$\leq 2 \mathrm{~cm}$ & $58(73,4)$ & $62(25,6)$ & \\
\hline$>2 \mathrm{~cm}$ & $21(26,6)$ & 1,80 & \\
\hline Lesion size mean (cm) & 1,99 & 242 &
\end{tabular}

Results A total of 321 patients constituted the study group. Among the study group, 79 (24.6\%) patients had margin positivity. Comparison of this group with 242 (75.4\%) margin negative patients revealed that abnormal pap-smear and HPV 16 and/or 18 positivity were significantly associated with margin positivity (table 1). Pap-smear abnormality ( $\geq$ ASC-US) was seen in $58(73.4 \%)$ of margine positive cases whereas only 118 (49.0\%) with margin negativity had abnormal smear $(p<0.001$, OR: $3.1 ; 95 \%$ CI: 1,7-5,6). This risk association did not differ for different Pap-smear abnormality thresholds (LSIL, HSIL etc). Being positive for HPV 16-18 was also a risk factor for margin positivity $(75.9 \%$ vs. $43.4 \%, \mathrm{p}<0.001$, OR: $4.4 ; 95 \% \mathrm{CI}: 2.45-7.96)$. However, neither age $(p=0.5)$ nor the lesion size $(\mathrm{p}=0.8)$ was a significant factor for margin positivity. Among 79 margin positive cases, 33 (41.7\%) had re-LEEP, 13 (16.5\%) had cold-knife conization, $13(16.5 \%)$ had hysterectomy, and $12(15.1 \%)$ were just followed-up while $8(10.2 \%)$ were lost to follow up after the LEEP procedure. Among patients who had re-LEEP or conization $(n=46), 7$ patients $(15,2 \%)$ had still positive surgical margine after the second procedure (5 in re-LEEP $(15,1 \%), 2$ in cold knife conization $(15,4 \%))$.

Conclusion Patients with HPV 16-18 and/or Pap-smear abnormality ( $\geq$ ASC-US) should be carefully evaluated before LEEP procedure for a possible margin positivity. In such cases, larger excisions may be considered to decrease the risk of margin positivity especially if the patient has no future fertility desire.

Disclosures No conflict of interest to declare.

\section{INDUCTION CHEMOTHERAPY FOR LOCALLY ADVANCED CERVICAL CANCER - YAY OR NAY?}

${ }^{1}$ Pedro Simões, ${ }^{1}$ João Godinho, ' Luísa Leal-Costa, ${ }^{1}$ Mafalda Casa-Nova, ${ }^{2}$ Fernando Igreja ${ }^{2}$ Gustavo Mendinhos, ${ }^{3}$ Rosa Madureira, ${ }^{4}$ Vanessa Monteiro, ${ }^{5}$ Vera Mendonça, ${ }^{1}$ José PassosCoelho. ${ }^{1}$ Hospital Beatriz Ângelo; Medical Oncology; ${ }^{2}$ Hospital Beatriz Ângelo; Obstetrics and Gynaecology; ${ }^{3}$ Hospital Beatriz Ângelo; Pathology; ${ }^{4}$ Hospital Beatriz Ângelo; Radiology; ${ }^{5}$ Centro Hospitalar Lisboa Norte, Hospital de Santa Maria; Radiotherapy

\subsection{6/ijgc-2020-ESGO.27}

Introduction/Background Definitive concurrent chemoradiation $[\mathrm{dChR}]$ is the standard treatment for locally advanced cervical cancer [LACC]. Although there's insufficient clinica evidence to support it, induction chemotherapy [iChT] 